Marquette University

e-Publications@Marquette

$1-1-2002$

\title{
Cultural Values and Important Possessions: A Cross-Cultural Analysis
}

John Watson

University of Canterbury

Steven Lysonski

Marquette University

Tamara Gillan

University of Canterbury

Leslie Raymore

Lincoln University

Accepted Version. Journal of Business Research, Volume 55, Number 11 (November 2002) pages 923-931. DOI: 10.1016/S0148-2963(01)00212-0. (C) 2002 Elsevier. Used with permission. 


\section{Cultural Values and Important Possessions: A Cross-Cultural Analysis}

John Watson, Steven Lysonski, Tamara Gillan, \& Leslie Raymore

\section{Abstract}

The logic behind globalized advertising appeals is based on the premise that cultural value systems are converging. Yet, there is no clear agreement regarding the superiority of standardized campaigns vs. localized ones. One reason for this lack of agreement deals with the extent to which various cultures share similar values. The goal of this study is to apply a relatively new framework dealing with value differences developed by Schwartz [Adv. Exp. Soc. Psychol. 25 (1992) 1.] to New Zealand and the USA by looking at the connection between these values and possessions. The hypotheses received mix support. The results confirm that New Zealanders are higher in Harmony and Affective Autonomy, and these values did, in part, affect possessions and reasons for owning them. New Zealanders' most valued possessions were for environmental reasons, but they were no more likely to mention enjoyment reasons than Americans. New Zealanders also did not mention recreational possessions as more important, contrary to one of the hypotheses. Nonetheless, the similarities between NZ and the USA were much greater than the differences. The study provides valuable insight into how the meanings of important possessions differ across cultures and illustrates the need to understand these differences when designing marketing communications and positioning products in foreign markets.

\section{Introduction}

As economic globalization intensifies, standardization of marketing mix elements can be an optimal approach to gain economies of scale. Indeed, global standardization can be seen in products, brands and advertising (van Raaij, 1997). Advertisers view standardized ad campaigns as a panacea to rising costs from localized advertising in each market. However, such standardization may not "fit" with the cultural variances around the world. De Mooij (1998) views the argument that cultures are developing similar values as superficial and misguided. She contends that national value systems are enduring, and these are integral to 
consumers' perceptions of advertising. According to DeMooij (1998, p. xiv) "The success of a business depends in the end on how well its products reach customers whose behavior is affected by values that may vary in all kinds of unexpected ways from those of the business' managers." To ignore these differences is to invite failure.

Although companies such as Coca-Cola, McDonalds and Ralph Lauren have succeeded with global advertising, many other firms have suffered from ignorance of cultural differences. A recent example occurred in Mexico in 1998 when women were offended by near-naked women in Wonderbra ads and boycotted their products until a particular advertising campaign was withdrawn. As firms extend their reach to foreign markets, such misunderstandings are likely. Hence, the crux of the problem is to identify differences in values, determine how they influence product choice, and, subsequently, advertise accordingly.

De Mooij (1998) contends that values are at the core of a culture and influence the perception of symbols and rituals, among others. These values are acquired by mental programming in the enculturation process. Without understanding a country's core cultural values, miscommunication in advertising is likely. These core values have a powerful influence on a country's characteristics and consumer behavior. Cultural values serve as the criteria its members use to determine what behavior is appropriate, to guide self-presentation and to justify their choices to others (Rokeach, 1973; Smith and Schwartz, 1997; Vinson et al., 1977b). Within the context of consumer behavior, cultural values have been used to explain patterns of behavior (Ford et al., 1995; Green and Alden, 1988; Tse et al., 1988; Wallendorf and Arnould, 1988) and differences in attitudes (Andrews et al., 1991; Ger and Belk, 1966; Grunert and Scherhom, 1990; Lee, 1993; Unger, 1995).

Despite Levitt's (1983) assertion that the globalization of markets is inevitable due to convergence of values, research suggests cultural differences persist. As such, research on values can illuminate critical marketing dimensions related to advertising and product positioning. Given this background, the goal of this study is to focus on the value differences between the USA and New Zealand (NZ) and how these affect possessions. Without understanding the importance of possessions, effective advertising appeals are unlikely, especially pattern advertising using similar appeals for global markets. Effective communication demands "knowing your customers" and the parameters that affect them such as cultural values.

Most cross-cultural studies provide comparisons among cultural groups without a strong underlying theory to explain differences. It is far better to explain observed differences with a theory (Smith and Schwartz, 1997). In this paper, the cultural-level value theory 
proposed by Schwartz (1994a) is used to explore the relationship between cultural values and important possessions. This theory provides a compelling and powerful perspective in which to examine cultural differences. The USA and NZ were chosen since they are culturally very similar, yet, past research has identified differences in consumption aspirations (Bryce and Olney, 1991), consumer perceptions (Gordon and McKeage, 1997) and both personal and cultural values (Schwartz, 1992, 1994a). Differences in values are likely to affect reasons for ownership of possessions (Prentice, 1987).

The outline of this paper is as follows. First, we provide background literature on cultural values, examine the Schwartz (1992) approach to measure culture and discuss the significance of understanding important possessions. The hypotheses are presented in the first part of the paper. After the methodology is discussed, the results concerning value differences and important possessions are provided. The paper concludes with implications and directions for future research.

\section{Background and Hypotheses}

"Culture" has been described as a society's personality or as the glue that binds people together. As an explanatory variable, it allows the investigation of a society's dimensions such as its values. When used to characterize and distinguish between cultures, values represent socially shared abstract ideas about what is good, right and desirable (Hofstede, 1994). According to Smith and Schwartz (1997, p. 80), five common features of values suggest that values: (1) are subjective and emotional beliefs; (2) refer to desirable goals and act as modes of conduct that promote these goals; (3) transcend specific actions and situations; (4) serve as guidelines to evaluate behavior; and (5) differ in how they are prioritized as an ordered system.

Individuals acquire values through socialization by dominant groups and through learning experiences (Schwartz, 1994a). Cultural values may take cognitive form as groups respond to their environment and express their responses in the "language of specific values about which they can then communicate" (Schwartz, 1994b, p. 21). Values may be "truisms"; people agree highly with the importance of particular values, but lack cognitive rationale (Maio and Olson, 1998). Many attitudes and behaviors are based on values and, collectively, they characterize cultures or nations.

Research has sought to identify "universal" values that characterize and distinguish cultures (Kluckholn and Strodtbeck, 1961; Rokeach, 1973; Hofstede, 1980, 1991; Schwartz, 1994a; Trompenaars, 1993). Hofstede's (1980) seminal study provided the first empirically and conceptually based set of value dimensions to compare cultures. The value dimensions 
by Hofstede are widely accepted, yet, there are serious limitations (Bond and Forgas, 1984; Leung, 1988; Kagitcibasi and Berry, 1989) concerning the number of values (Hofstede, 1980; Schwartz 1994a), their universality (Shackleton and Ali, 1990; Schwartz, 1994a) and the nature of the data (Schwartz, 1994a). The Value Survey (1973) with 36 values was one of the initial approaches to measure values in marketing (Vinson et al., 1977a). Subsequently, Kahle and Timmer (1983) developed a more parsimonious measure using nine values called the List of Values (LOV). Unfortunately, these approaches have been criticized as ethnocentric since they reflect USA culture (de Mooij 1998).

Recently, Schwartz (1994a) developed a new theory of cultural-level values and a different method for measuring such values. To overcome limitations of previous research on values, Schwartz used both Western and non-Western sources to derive cultural value dimensions and controlled for meaning equivalence. The Schwartz cultural-level value system, exhibiting both external and convergent validity, represents the most promising framework for cross-cultural comparison of universal values (Bond and Smith, 1996). For this reason, we used the Schwartz cultural-level approach to values.

\subsection{Schwartz's Cultural-level Values}

Schwartz (1992) proposed that values represent a structure of interacting belief systems, the collection of which constitutes culture. Undergirding this conceptualization, Schwartz (1994a) developed a theory of conflicts and compatibilities among seven value types as follows:

1. Conservatism: maintenance of the status quo, proprietary and restraint of actions that might disrupt group solidarity and traditional order (e.g., social order, respect for tradition, family security).

2. Intellectual Autonomy: independent ideas and the rights of the individual to pursue his/her own intellectual directions (e.g., curiosity, creativity, broad mindedness).

3. Affective Autonomy: individual pursuit of affectively positive experiences (e.g., pleasure, exciting life, a varied life).

4. Hierarchy: legitimacy of an unequal distribution of power roles and resources (e.g., social power, authority, humility, wealth).

5. Egalitarian Commitment: transcendence of selfish interests to interests, which serve the common good (e.g., equality, social justice, freedom, responsibility and honesty).

6. Mastery: getting ahead through self-assertion (e.g., ambition, success, competence).

7. Harmony: fitting harmoniously into the environment (e.g., unity with nature, protecting the environment). 
Smith and Schwartz (1997, p. 86) postulated that each value type has "psychological, practical and social consequences that may conflict or be compatible with the pursuit of other types." For example, if Autonomy is emphasized within a culture, the importance of Conservatism (its opposite type) is depressed. "This is necessary in order to ensure consistent socialization and reinforcement of behavior and to foster smooth institutional functioning" (Schwartz 1994a, p. 98).

Schwartz (1994a) developed an instrument to measure cultural-level values by selecting specific values to represent each value type; these were drawn from previous research, including Rokeach's (1973) value survey and from religious and philosophical writings found in different cultures. By consulting survey instruments developed in other cultures (Braithwaite and Law, 1985; Chinese Culture Connection, 1987; Hofstede, 1980), Schwartz (1994a) avoided imposing a Western-imposed etic. The Schwartz approach provides a cross-culturally validated instrument for measuring cultural-level values and a comprehensive, near universal set of value types for studying cultural differences. Data collected in 54 countries from approximately 44,000 subjects confirmed the theorized content and structure of the cultural-level value types (Smith and Schwartz, 1997). In addition, Schwartz ranked nations on each of the seven values. This approach can identify cultural values; these values then can be used to understand the meaning that people attach to products as discussed below.

Schwartz's (1994a) ordering of nations for the cultural-level values reveals that NZ and the USA are different on two value types only. Specifically, New Zealanders value Affective Autonomy and Harmony more than Americans do (Schwartz, 1994a). Therefore, the first hypothesis can be stated as:

Hypothesis 1: Americans, in comparison to New Zealanders, have lower scores on Affective Autonomy and Harmony.

\subsection{Cultural Values and the Private Meanings of Important Possessions}

McCracken (1988) suggests that the identity of products is given meaning by the way it is transmitted in the cultural system, while Belk (1988) views our identities as constructed by our possessions (Belk, 1988). Hence, a person's most important possessions reflect personal values and inner self (Csikszentmihalyi and Rochberg-Halton 1981; Wallendorf and Arnould, 1988). Owners of possessions cultivate private meanings of possessions reflective of their values (Csikszentmihalyi and Rochberg-Halton 1981; Richins 1994a). The collectivity of these private meanings relates to the totality of an individual's thoughts and feelings about 
the importance of an object (Richins, 1994b). These private meanings of their possessions characterize a person's values (Csikszentmihalyi and Rochberg-Halton, 1981).For instance, a person who values "conservatism" may treasure an antique Hamilton pocket watch as a family heirloom because it symbolizes family ties and heritage. Alternatively, a person who values "mastery" may treasure the same watch because it symbolizes prestige and enhances one's self-concept.

An individual cultivates both social and personal meanings through interactions with an object over time (Richins, 1994b); such private meanings of possessions are shaped by and reflect one's culture (Grunert and Juhl, 1995; Rokeach, 1973; Smith and Schwartz, 1997; Vinson et al., 1977b). Hence, the private meanings associated with important possessions should reflect dominant cultural values. Therefore, the following hypotheses can be stated:

Hypothesis 2: New Zealanders, in comparison to Americans, evaluate important possessions $(A)$ in terms of enjoyment because of their higher levels of Affective Autonomy and $(B)$ in terms of unity with nature and protection of the natural environment because of their higher levels of Harmony.

\subsection{Important Possessions}

Affective Autonomy, expressed through enjoying life and pleasure, relates to freedom of individual feeling and action. Accordingly, possessions that provide independence, enjoyment or sensory pleasure may reflect affective freedom. The value Harmony focuses on the environment and unity with nature. While it is difficult to own "the environment," some possessions may embody this value since they allow aesthetic and physical awareness of the natural world. Although New Zealanders have higher levels of Affective Autonomy and Harmony than Americans (Schwartz, 1994a), explaining how these differences affect important possessions is problematic. For example, a person who values his/her wedding ring as most important seems to differ markedly from a person who values his/her sports car. However, on closer examination, both people may identify interpersonal reasons for the importance of these possessions. The wedding ring may be cherished for its symbolic association with a spouse, while the sports car may be favored because it came from a loved one and symbolizes the importance of that relationship. Hence, different types of possessions may provide similar private meanings. In contrast, the same possession can provide radically different private meanings to different individuals. For example, recreational equipment such as a bicycle could be valued because of its technical superiority to achieve athletic excellence (i.e., mastery). Alternatively, the individual may value quiet bike rides in the country and viewing nature's beauty (i.e., Harmony). Consequently, the purchase of the 
bike may be motivated by values that are polar opposites, depending on the person.

Because cultural values influence self-images (Best and Williams, 1994; Markus and Kitayama, 1991), cultural-level values may also influence peoples' choices of their most important possessions. Hence, the following hypothesis can be stated:

Hypothesis 3: New Zealanders, in comparison to Americans, identify their most important possessions that reflect their higher ratings of Affective Autonomy and Harmony (Schwartz, 1994a).

\section{Method}

\subsection{Data Collection}

Data were collected from the general population by mail surveys administered in the USA and NZ. The USA data were obtained by selecting systematically 700 names from telephone directories in a Mid-Atlantic state. Fundamental principles from the Dillman (1978, 1984) "Total Design Method" for telephone and mail surveys were used. The NZ sample of 1000 respondents was drawn systematically from the electoral roll whereby registered voters had an equal opportunity of selection. Over $90 \%$ of the NZ population over the age of 18 are registered voters. Usable questionnaires were returned by $46 \%(\mathrm{~N}=322)$ of those sampled in the USA and $45 \%(\mathrm{~N}=446)$ in the $\mathrm{NZ}$ sample.

\subsubsection{Measures}

\subsubsection{Values}

The Schwartz (1994a) Value Inventory and the recommended procedure were used to measure the importance of the seven culture-level value types. The instrument asks respondents to rank and then rate various values. It consists of 45 items (as featured in Table 1) that measure the seven value types: Hierarchy, Mastery, Affective Autonomy, Intellectual Autonomy, Egalitarian Commitment, Harmony, and Conservatism. The alpha coefficients (to measure reliability) for the USA and NZ samples were respectively: .60 and .62 for Hierarchy; .66 and .60 for Mastery; .68 and .75 for Affective Autonomy; .61 and .59 for Intellectual Autonomy; .73 and .72 for Egalitarian Commitment; .78 and .73 for Harmony; and .80 and .83 for Conservatism. These reliabilities are comparable to those reported by Schwartz (1994a) and sufficient for reliability.

\subsubsection{Important possessions.}

Respondents identified their most important possessions by responding to the following statement: "Many people have a few possessions that they care a lot about or that 
are especially important to them. In the space below, please identify your most prized possessions and explain why they are important to you." Respondents were asked to list their three most important possessions and the reasons for their importance.

Using Richins (1994a,b) framework, possessions were coded using 13 groups as follows: sentimental objects, assets, transportation, practical objects, recreational, personal appearance, extension of self, aesthetic and other. Given the limitations in her categorization scheme, three additional categories were added: (1) people/friendships; (2) pets; and (3) possessions such as plants and gardens that emphasize the environment. The reasons given for the importance of the possessions were content analyzed using the coding scheme developed by Richins (1994a,b), which was initially designed to examine the relationship between possessions and personal values. The categories were utilitarian, enjoyment, interpersonal ties, identity, financial aspects, appearance related, ownership/control and other/ unclassified. Because Richins developed the scheme using a different population, additional content categories (which emerged from the data) were also included. These five additional categories concerned possession value based on educational value, information value, irreplaceability, health and the object's ability to create unity with nature or to protect the environment.

Both possessions and reasons were content analyzed independently by two judges for the American sample and two different judges for the NZ sample. Because of some language nuances, it was appropriate to use judges familiar with their colloquialisms and jargon. These judges were trained in advance to insure consistent coding. Any disagreements were resolved through discussion between judges. For possessions, coder agreement was 95\% for the USA sample and $97 \%$ for the NZ sample. For the reasons of their importance, coder agreement was $94 \%$ for NZ sample and $93 \%$ for the US sample.

\subsubsection{Sample Characteristics}

An attempt was made to match the sampling frames with national proportions on three demographic dimensions: location of residence (i.e., urban, nonurban); income; and age. These three variables were selected because of their potential impact on questions related to values and consumption. For location of residence, both samples for the USA and NZ were proportional to their national breakdowns. For the US, $63 \%$ were from an urbanized area and 37\% were from a nonurbanized area (US Bureau of Census, 1990). Similarly, the NZ respondents were $62 \%$ urban and $38 \%$ nonurban (Statistics NZ, 1997). Regarding age and income, the samples for the USA and NZ were also comparable to the general population for each country. 


\section{Analysis and Results}

\subsection{Testing of Hypothesis 1: Comparison of Cultural-level Values}

Repeated-measures analysis of variance (ANOVA) was used to test for value differences. Country (USA/NZ) served as the independent variable, and the seven cultural-level value types - Conservatism, Egalitarian Commitment, Harmony, Mastery, Hierarchy, Affective Autonomy and Intellectual Autonomy - served as the dependent variables in the analysis. The traditional univariate $F$ statistics resulting from simple ANOVAs were not valid because of the correlations among the value types. In order to test the simple main effects of country (USA/NZ), it was necessary to calculate the error estimate pooled between-and within-subjects variation (Winer et al., 1991).

Hypothesis 1 was supported as shown by the statistical differences on three of the values in Table 2. Specifically, the USA respondents were higher in Conservatism, lower in Harmony, and lower in Affective Autonomy. Although this result on Conservatism differs from Schwartz (1994a), it is probably because Schwartz's respondents were primarily schoolteachers - a highly educated group - while those in our sample were a cross section of the general population in NZ.

\subsection{Testing of Hypothesis 2: Private Meanings of Possessions}

With respect to the private meanings of possessions, it was hypothesized that New Zealanders would be more likely to name reasons of enjoyment and environment for the importance of their prized possessions. The USA sample provided 1132 reasons for valuing the 823 possessions they characterized as important — an average of 1.4 reasons per possession. New Zealanders provided 1632 reasons for valuing their 1047 most important possessions - an average of 1.6 reasons per possession. Table 3 features the categorization of these reasons. 
To determine if New Zealanders provided different private meanings for the importance of their prized possessions compared to Americans, $z$ tests for differences of proportions were also used. Hypothesis 3 was only partially supported. Consistent with their value of Harmony, Table 3 shows that New Zealanders listed environmental reasons for valuing their important possession more frequently than Americans $(z=3.43 ; P<.001)$. However, New Zealanders were no more likely to mention enjoyment as a reason for valuing their possessions $(\mathrm{z}=1.51, \mathrm{P}<.10)$, which was contrary to our expectations given the value of Affective Autonomy for New Zealanders. Other differences between the two countries were also evident. New Zealanders were more likely than Americans to value possessions for interpersonal $(z=-4.05, P<.01)$ and financial reasons $(z=-2.99, P<.01)$, but Americans were more likely to value possessions for utilitarian $(z=2.53, P<.05)$, appearance-related $(z=4.06$, $P<.001)$ and ownership and control $(z=3.60, P<.001)$ reasons.

A final analysis was conducted to see if New Zealanders and Americans identify different reasons why the same type of possession is important (e.g., Are recreational possessions predominantly valued for enjoyment reasons, or assets for financial reasons?). Previous studies investigating the private meanings of possessions have not examined this relationship (e.g., Prentice, 1987; Richins, 1994a,b). Findings indicate that New Zealanders, compared to Americans, were more likely to value assets $(z=-2.3, P<.05)$ and recreational items $(\mathrm{z}=-2.63, \mathrm{P}<.01)$ for interpersonal reasons and transportation $(\mathrm{Z}=-2.45, \mathrm{P}<.05)$ for financial reasons. In contrast, Americans were more likely to value transportation $(z=3.41$, $P<.001)$ and appearance-related possessions $(z=2.46, P<.001)$ for interpersonal reasons.

\subsection{Testing of Hypothesis 3: Types of Possessions}

z Tests for differences of proportions were used to test whether New Zealanders and Americans differed in the types of possessions they identified as important. These results appear in Table 4 and partially support Hypothesis 3 . Respondents in the USA and NZ listed on average 2.5 and 2.4 valued possessions, respectively. New Zealanders were more likely to identify environmental possessions as important $(\mathrm{z}=-3.88, \mathrm{P}<.001)$, but were less likely to identify recreational possessions as important $(\mathrm{z}=2.01, \mathrm{P}<.05)$. Americans were also more likely to identify practical objects $(z=3.47, P<.001)$, appearance-related possessions $(z=7.41$, $P<.001)$ and aesthetic objects $(z=5.34, P<.001)$ as important. New Zealanders were more likely to identify sentimental objects $(Z=-5.63, P>.001)$ and possessions representing extensions of the self $(\mathrm{z}=-3.37, \mathrm{P}<.001)$ as important. In addition, New Zealanders were more likely to identify people/friendships as their most important possessions $(\mathrm{Z}=-2.67, \mathrm{P}<.01)$ than Americans. 


\section{Discussion and Implications}

The first research question guiding this study concerned the differences in cultural values between NZ and the USA. New Zealanders value Harmony and Affective Autonomy more than Americans. The latter finding is consistent with previous research examining differences between the USA and NZ (cf. Bryce and Olney, 1991). Unlike the Schwartz's $(1994 a, b)$ findings, Americans, in general, placed more importance on the Conservatism value than those in NZ.

When examining how value differences were related to the important possessions for respondents from the two countries (i.e., Hypothesis 3), NZ and the United States are more similar than distinct. Their cultural-level value hierarchies are nearly the same, and the top four categories in which respondents identified important possessions were almost identical. The four categories for New Zealanders were assets (23\%), sentimental objects (21\%), transportation (15\%) and recreation objects (9\%). Similarly, the top four categories identified by Americans were assets (22\%), transportation (16\%), recreation objects (12\%) and sentimental objects $(11 \%)$. Only the frequency of these categories differed between the two countries. These frequencies, however, were most noticeable and quite substantial for interpersonal items.

New Zealanders were far more likely to identify sentimental objects and people/friendships as important possessions, possessions that have a retrospective orientation. Sentimental objects such as family heirlooms and photos act as symbols of familial and personal history and illustrate an outlook more focused on the past. Likewise, possessions representing extensions of the self, such as souvenirs and trophies, serve as records of previous accomplishments. In comparison, Americans seem more pragmatic, concerned with the present. The recreational possessions (e.g., sporting equipment) and practical objects (e.g., appliances and tools) identified by Americans as important offer their owners immediate benefits. Hence, the finding may apply to the design of advertising for the two countries; appeals drawing on nostalgia are likely to be more effective in NZ, whereas American consumers may be more drawn to products that satisfy immediate desires.

Americans were also more likely to value personal appearance (e.g., clothing and jewelry) and aesthetic (e.g., paintings and antiques) possessions. Wallendorf and Arnould (1988) theorize that the value of aesthetic possessions often relates to a need to enact social differentiation. Art objects, particularly rare and unique ones, help people to express their individuality and, thus, to differentiate themselves from mainstream consumer culture. The fact that Americans were more likely to value "individuating" objects (e.g., artwork) might be 
partially explained by their vertically individualistic orientation, which promotes a self-difference from the others (see Triandis and Gelfand, 1998). In contrast, New Zealanders are discouraged from standing out, what they refer to as "Tall Poppy Syndrome," and individuals within their society are encouraged to blend in with the others (what Triandis and Gelfand, 1998 call a horizontally individualistic orientation). Advertisers who do not understand this distinction could be in for disastrous results if they placed advertisements with "individuating" themes in NZ. Such appeals are likely to be viewed negatively and could have an undesirable effect on the image of the brand.

The value-behavior relationship was also examined in more depth by focusing on the different reasons why specific types of possessions were important for respondents from the two countries. Hypothesis 2 was partially supported in that New Zealanders were much more likely to identify plants and gardens as important possessions than were Americans, and these possessions were more likely to be valued for environmental reasons. This result is consistent with the differential importance that New Zealanders place on the value Harmony. When recreational possessions were examined, however, the results were not consistent with our expectations. New Zealanders, in comparison to Americans, identify interpersonal reasons for the importance of recreational items, but they are no more likely to express enjoyment reasons for recreational items than Americans.

Other results offer other insights not associated with the hypotheses. For example, interesting results were found for home ownership. Compared to New Zealanders, Americans were significantly more likely to express "identity" and "ownership" reasons why their assets (i.e., houses) were important. Although neither group was significantly more or less likely to identify houses as important possessions, their reasons were different providing a significant contrast in value systems. Whereas New Zealanders were more concerned with the security provided by their homes and the interpersonal relationships that are maintained there, Americans stated that owning a home was valued because of the accomplishment it signified; the house was theirs, a part of who they are, and what they have done.

The goal of this research was to apply Schwartz's theory of values to explain cross-cultural differences in possessions and the concomitant meaning of these for marketing and advertising practice. The results suggest that this theoretical framework does explain cross-cultural differences and can be used to garner insight into how the meanings of important possessions differ across cultures. These findings offer an understanding of why people in different cultures buy things and why they view some possessions as more important than the others. Indeed, there does seem to be a connection between values and 
possessions; a connection that marketers can exploit. The results that were contrary to those hypothesized need further inquiry. Perhaps, there are other forces operating in these cultures that were not identified by the Schwartz typology. Future research needs to probe this concern.

In summary, the Schwartz approach clearly has practical use. Even in situations in which such differences are very subtle, as in the case of NZ and the United States, this information can be very useful in the design of advertising appeals. Despite Levitt's (1983) argument that consumers throughout the world are becoming so similar that the globalization of markets is inevitable, there is still a case to be made for the importance of cross-cultural consumer research. Differences do exist, and a lack of recognition of this fact can unnecessarily expose companies to risks that could have easily been avoided, even in countries viewed as culturally very similar. This type of research provides an opportunity to improve our understanding of consumption and to better understand consumers from an international perspective - a fundamental concern as globalization accelerates. 


\section{References}

Andrews J, Lysonski S, Durvasula S. Understanding cross-cultural student perceptions of advertising in general: implications for advertising educators and practitioners. J Advertising 1991;20(2):15-28.

Belk RW. Possessions and the extended self. J Consum Res 1988;15: 139-68 (September).

Best DL, Williams JE. Masculinity/femininity in the self and ideal-self descriptions of students in 14 countries. In: Bouvy AM, Vande Vijver F, Boski P, Schmitz P, editors. Journeys into cross-cultural psychology. Lisse, Netherlands: Swets and Zetlinger, 1994. p. 297-306.

Bond MH, Forgas JP. Linking person perception to behavior intention across cultures: the role of cultural collectivism. J Cross-Cult Psychol 1984;15:337-52.

Bond MH, Smith PB. Cross-cultural social and organizational psychology. Annu Rev Psychol 1996;47:205-35.

Braithwaite VA, Law HG. Structure of human values: testing the adequacy of the Rokeach value survey. J Pers Soc Psychol 1985;49:41-50.

Bryce W, Olney TJ. Gender differences in consumption aspirations: a cross-cultural appraisal. Soc Behav Pers 1991;19(4):237-53.

Chinese Culture Connection. Chinese values and the search for culture-free dimensions of culture. J Cross-Cult Psychol 1987;18:143-64.

Csikszentmihalyi M, Rochberg-Halton E. The meaning of things: domestic symbols and the self. Cambridge: Cambridge Univ. Press, 1981.

De Mooij M. Global marketing and advertising: understanding cultural paradoxes. London: Sage Publications, 1998.

Dillman DA. Telephone surveys: the total design method. New York: Wiley, 1978.

Dillman DA. The importance of adhering to details of the total design method (TDM) for mail surveys. New Dir Program Eval 1984;21: 49-64 (March).

Ford JB, LaTour MS, Henthorne TL. Perception of marital roles in purchase decision processes: a cross-cultural study. J Acad Mark Sci 1995;23(2): 120- 31.

Ger G, Belk RW. Cross-cultural differences in materialism. J Econ Psychol 1966;17(1):5577.

Gordon ME, McKeage K. Relationship marketing effectiveness: differences between women in NZ and the United States. In: Pride W, Hult G, editors. Enhancing knowledge development in marketing, vol. 8. Chicago: AMA, 1997. p. 250-3.

Green RT, Alden DL. Functional equivalence in cross-cultural consumer behavior: gift giving in Japan and the United States. Psychol Mark 1988;5(2):155-68. 
Grunert SC, Scherhom G. Consumer values in West Germany underlying dimensions and cross-cultural comparison with North America. J Bus Res 1990;20(2):97-107.

Grunert SC, Juhl HJ. Values, environmental attitudes, and buying of organic foods. J Econ Psychol 1995;16(1):39-62.

Hofstede G. Cultures consequences: international differences in work-related values. Beverly Hills: Sage, 1980.

Hofstede G. Cultures and organisations: software of the mind. London: McGraw-Hill, 1991.

Hofstede G. Management scientists are human. Manage Sci 1994;40:4-13 (January).

Kagitcibasi C, Berry JW. Cross-cultural psychology: current research and trends. Annu Rev Psychol 1989;40:493-531.

Kahle LR, Timmer GS. A theory and method for studying values and social change: adaptation in America. New York: Praeger, 1983.

Kluckholn FR, Strodtbeck FL. Variations in value orientations. Evanston, IL: Row Peterson, 1961.

Lee W. Acculturation and advertising communication strategies: a cross-cultural study of Chinese and Americans. Psychol Mark 1993;10(5): 381-97.

Leung K. Some determinants of conflict avoidance. J Cross-Cult Psychol 1988;19:125-36.

Levitt T. The globalization of markets. Harv Bus Rev 1983;61:92-102 (May-June).

Maio GR, Olson JM. Values as truisms: evidence and implications. J Pers Soc Psychol 1998;74(2):294 -311.

Markus HR, Kitayama S. Culture and the self: implications for cognition, emotion and motivation. Psychol Rev 1991;98(2):224-53.

McCracken G. Culture and consumption: new approaches to the symbolic character of consumer goods and activities. Bloomington: Indiana Univ. Press, 1988.

Prentice DA. Psychological correspondence of possessions, attitudes, and values. J Pers Soc Psychol 1987;53:993-1003 (December).

Richins M. Social possessions and the expression of material values. J Consum Res 1994a;21:522-33 (December).

Richins M. Valuing things: the public and private meanings of possessions. J Consum Res 1994b;21:504-21 (December).

Rokeach M. The nature of human values. New York: Free Press, 1973.

Schwartz SH. Universals in the structure and content of values: theoretical advances and empirical tests in 20 countries. In: Zanna MP, editor. Advances in experimental social psychology, vol. 25. Orlandd, FL: Academic Press, 1992. p. 1-65.

Schwartz SH. Beyond individualism/collectivism: new cultural dimensions of values. In: Kim 
U, Triandis HC, Kagitcibasi C, Choi SC, Yoon G, editors. Individualism and collectivism: theory, method and applications. Thousand Oaks, CA: Sage, 1994a. p. $85-119$.

Schwartz SH. Are there universal aspects in the structure and contents of human values? J Soc Issues 1994b;50(4):19-45.

Shackleton VJ, Ali AH. Work-related values of managers: a test of the Hofstede model. J Cross-Cult Psychol 1990;21:109-18.

Smith PB, Schwartz SH. Values. In: Berry JW, Segall MH, Kagitcibasi C, editors. Handbook of cross-cultural psychology, vol. 3. Boston: Allyn and Bacon, 1997. p. 150-66.

Statistics NZ. 1996 Census of population and dwellings. Wellington, NZ: Statistics NZ, 1997. Triandis HC, Gelfand MJ. Converging measurement of horizontal and vertical individualism and collectivism. J Pers Soc Psychol 1998;74(1): 118-28.

Trompenaars F. Riding the waves of culture. London: Brealey, 1993.

Tse DK, Lee K, Vertinsky I, Wehrung DA. Does culture matter? A cross-cultural study of executives' choice, decisiveness, and risk adjustment in international marketing. $\mathrm{J}$ Mark 1988;52(4):81-95.

Unger LS. Observations: a cross-cultural study on the affect-based model of humor in advertising. J Advertising Res 1995;35(1):66-71.

US Bureau of the Census. Statistical abstract of the United States 1990 110th ed. Washington, DC: US Government Printing Office, 1990.

Van Raaij WF. Globalisation of marketing communication? J Econ Psychol 1997;18:259-70.

Vinson DE, Munson JM, Nakanahi M. An investigation of the rokeach value survey for consumer research applications. In: Pereault WD, editor. Advances in consumer research, vol. 4. Atlanta, GA: Association for Consumer Research, 1977a. p. 262-6.

Vinson DE, Scott JE, Lamont LM. The role of personal values in marketing and consumer behavior. J Mark 1977b;44-50 (April).

Wallendorf M, Arnould EJ. 'My favorite things': a cross-cultural inquiry into object attachment, possessiveness and social linkage. J Consum Res 1988;14:531-47 (March).

Winer BJ, Brown DR, Michels KM. Statistical principles in experimental design. NY: McGraw-Hill, 1991. 


\section{Appendix}

\section{Table 1: Schwartz's seven cultural-level value types}

\begin{tabular}{ll}
\hline Mastery & Conservatism \\
- Successful & - Clean \\
- Capable & - National security \\
- Ambitious & - Reciprocation of favors \\
- Independent & - Social order \\
- Daring & - Pamily security \\
- Choosing own goals & - Honoring parents and elders \\
Hierarchy & - Obedient \\
- Social power & - Self-discipline \\
- Authority & - Devout \\
- Wealth & - Humble \\
- Influential & - Preserving public image \\
- Humble & - Forgiving \\
& - Wisdom
\end{tabular}

Harmony

- Protecting the environment

Affective Autonomy

- Unity with nature

- A world of beauty

Egalitarian Commitment

- Helpful

- Honest

- Loyal

- Responsible

- Social justice

- A varied life

- An exciting life

- Pleasure

- Enjoying life

- Equality

- A world at peace

Intellectual Autonomy

- Creativity

- Broad minded

- Curious

- Accepting my position in life 
Table 2: Differences between Americans and New Zealanders for cultural-level values ANOVAs

\begin{tabular}{|c|c|c|c|c|c|c|}
\hline \multirow[t]{3}{*}{ Value type } & \multicolumn{4}{|c|}{ Country } & \multirow[t]{3}{*}{$F$ value } & \multirow[t]{3}{*}{$P$} \\
\hline & \multicolumn{2}{|l|}{ USA } & \multicolumn{2}{|l|}{$\mathrm{NZ}$} & & \\
\hline & Mean $^{a}$ & Standard deviation & Mean $^{\mathrm{a}}$ & Standard deviation & & \\
\hline Mastery & 5.46 & 0.92 & 5.49 & 1.09 & 0.49 & $>.10$ \\
\hline Hierarchy & 3.40 & 1.02 & 3.54 & 1.09 & 0.07 & $>.10$ \\
\hline Conservatism & 5.42 & 0.88 & 5.24 & 0.97 & 12.71 & .001 \\
\hline Harmony & 4.70 & 1.47 & 5.25 & 1.39 & 26.13 & .001 \\
\hline Egalitarianism & 5.96 & 0.86 & 6.08 & 0.85 & 0.21 & $>10$ \\
\hline Intellectual Autonomy & 5.04 & 1.21 & 5.24 & 1.16 & 1.55 & $>10$ \\
\hline Affective Autonomy & 4.70 & 1.15 & 5.09 & 1.29 & 16.25 & .001 \\
\hline
\end{tabular}

Note: The mean importance rating for each value type was simply the average of the individual values that represent that particular value type. 
Table 3: Differences in private meanings of possessions for Americans and New Zealanders

\begin{tabular}{|c|c|c|c|c|c|}
\hline \multirow[t]{2}{*}{ Meaning } & \multicolumn{4}{|l|}{ Country } & \multirow[t]{2}{*}{$z$} \\
\hline & USA $(n=322)$ & Percentage (\%) & $\mathrm{NZ}(n=448)$ & Percentage (\%) & \\
\hline \multicolumn{6}{|l|}{ Utilitarian } \\
\hline Provides a necessity & 118 & & 131 & & \\
\hline Enhances work efficiency or effectiveness & 15 & & 30 & & \\
\hline Valued for performance or functional attributes & 46 & & 41 & & \\
\hline Provides freedom, independence & 45 & & 60 & & \\
\hline Total & 224 & 20 & 262 & 16 & $2.53^{*}$ \\
\hline \multicolumn{6}{|l|}{ Enjoyment } \\
\hline Provides pleasure, allows enjoyable activity & 119 & & 164 & & \\
\hline Provides relaxation, comfort, escape & 84 & & 118 & & \\
\hline Provides companionship & 29 & & 15 & & \\
\hline Total & 232 & 20 & 297 & 18 & 1.51 \\
\hline \multicolumn{6}{|l|}{ Interpersonal ties } \\
\hline Symbolic ties to others & 111 & & 378 & & \\
\hline Gifts & 63 & & 52 & & \\
\hline Symbols of familial history & 60 & & 83 & & \\
\hline Facilitates interpersonal ties & 63 & & 33 & & \\
\hline Total & 297 & 26 & 546 & 33 & $-4.05 * * *$ \\
\hline \multicolumn{6}{|l|}{ Identity } \\
\hline Part of the self; self-expression & 30 & & 57 & & \\
\hline Allows creative expression & 19 & & 34 & & \\
\hline Represents accomplishment; is a source of pride & 87 & & 85 & & \\
\hline Symbolizes personal history & 55 & & 86 & & \\
\hline Total & 191 & 17 & 262 & 16 & 0.92 \\
\hline \multicolumn{6}{|l|}{ Financial aspects } \\
\hline Investment values; equity; financial security & 25 & & 75 & & \\
\hline Expensive item & 20 & & 33 & & \\
\hline Total & 45 & 4 & 108 & 7 & $-2.99 * *$ \\
\hline \multicolumn{6}{|l|}{ Appearance related } \\
\hline Enhances appearance or self-feelings & 13 & & 13 & & \\
\hline References to possession's appearance & 32 & & 12 & & \\
\hline Total & 45 & 4 & 25 & 2 & $4.06^{* * *}$ \\
\hline Ownership; control & 36 & 3 & 20 & 1 & $3.60^{* * *}$ \\
\hline Environmental & 0 & 0 & 17 & 1 & $-3.43^{* * *}$ \\
\hline \multicolumn{6}{|l|}{ Other/unclassified } \\
\hline Education & 14 & & 16 & & \\
\hline Information & 5 & & 20 & & \\
\hline Irreplaceable & 5 & & 39 & & \\
\hline Health & 0 & & 19 & & \\
\hline Other & 38 & & 1 & & \\
\hline Total & 62 & 5 & 95 & 6 & -0.38 \\
\hline Grand total & 1132 & 100 & 1632 & 100 & \\
\hline
\end{tabular}

19 Watson, Lysonski, Gillan, \& Raymore 
Table 4: Differences in type of possessions for Americans and New Zealanders

\begin{tabular}{lccccc}
\hline Characteristic & Country & & & & $z$ \\
\cline { 2 - 5 } & USA $(n=322)$ & Percentage $(\%)$ & NZ $(n=448)$ & Percentage $(\%)$ & \\
\hline Recreational & 99 & 12 & 96 & 9 & $2.01^{*}$ \\
Environmental & 0 & 0 & 19 & 2 & $-3.88^{* * *}$ \\
Sentimental objects & 90 & 11 & 216 & 21 & $-5.63^{* * *}$ \\
Assets & 181 & 22 & 245 & 23 & -0.72 \\
Transportation & 130 & 16 & 154 & 15 & 0.65 \\
Practical objects & 69 & 8 & 47 & 4 & $3.47^{* * *}$ \\
Appearance related & 81 & 10 & 21 & 2 & $7.41^{* * * *}$ \\
Extension of self & 11 & 1 & 41 & 4 & $-3.37^{* * *}$ \\
Aesthetic & 59 & 7 & 22 & 2 & $5.34^{* * *}$ \\
People/friendships & 43 & 5 & 88 & 8 & $-2.67^{* *}$ \\
Pets & 27 & 3 & 28 & 3 & 0.77 \\
Health and life & 0 & 0 & 25 & 2 & $-4.46^{* * *}$ \\
Other & 33 & 4 & 45 & 4 & -0.31 \\
Grand total & 823 & 100 & 1047 & 100 & \\
\hline
\end{tabular}

* $P<.05$.

** $P<.01$.

$* * * \quad P<.001$. 